Japanese Yearbook on Business History - 1998 / 15

\title{
Marine Transport Management in Early-Modern Japan
}

\author{
Masahiro Uemura \\ Wakayama University
}

$\int$

APAN IS SURROUNDED by the sea, and in the Edo Period exchanges between different regions was frequently carried out via the sea. There is no need to emphasize the importance of maritime traffic prior to the development of rail and road networks in modern times. Also, what can be said of maritime traffic in early-modern society is that, because of the national isolation policy, direct trade with other countries was cut off, and as a result the development of coastal routes matured within the framework of early-modern society, and the economic nature of the kaisen (large Japanese-style cargo vessels used for carrying merchandise along Japan's coasts; hereafter, cargo vessels) structure that accompanied that development was raised to its highest limits. ${ }^{1}$

1 The following works deal with the history of marine transport in early-modern Japan: Fukui Prefectural Library and Fukui Local Records Kondankai, eds., Nihonkai kaiun-shi no kenky $\bar{u}$ [Studies of the history of marine transport on the Sea of Japan] (Fukui Kyōdoshi Kondankai, 1967); Takeshi Toyoda and Kōta Kodama, eds., Kōtsū-shi [The history of transportation] (Yamakawa Shuppansha, 1970); Manabu Yunoki, ed., Nihon suijō kōtsü-shi ronshü [Essays on the history of water transport in Japan], 6 vols. (Bunken Shuppan, 1986-96); Manabu Yunoki, Kinsei kaiun-shi no kenky $\bar{u}$ [Studies of the history of earlymodern marine transport] (Hõsei University Press, 1979); Tamotsu Takase, Kaga han kaiun-shi no kenkyū [Studies of the history of marine transport in the Kaga clan] 
The aim of this article will be to shed light on the distinctive features of marine transport in the Edo Period, and to show the extent to which Japan's early-modern marine transport management system was a rational scheme within the framework of the Edo Period. ${ }^{2}$

\section{THE SIGNIFICANCE OF RESEARCH ON THE HISTORY OF MARINE TRANSPORT IN EARLY-MODERN JAPAN}

We can discuss the significance of research on the history of marine transport in early-modern Japan from two aspects. The first aspect is that of the economic environment and social conditions surrounding the early-modern cargo vessels and the economicalness of cargo vessel construction. The second aspect is the special characteristics of cargo vessel functions.

Even in terms of the structure of early-modern society, the importance of the role played by early-modern marine transport cannot be denied. Since the Bakuhan system (government by a shogun at the top, under which were daimyo domains) had as its foundation the kokudaka system, under which the value of a landholding was assessed in terms of yield by koku (one koku was 4.96 bushels) of rice, conversion of rice paid in taxes into money on the market became necessary, and this assumed a certain amount of commodity production and commodity distribution. Similarly, the separation between warriors and farmers (heinobunri) led to the concentration of warriors and townspeople in the castle towns and the concentration of farm-

(Yūzankaku, 1979) and Kaga han no kaiun-shi [The history of Kaga clan marine transport] (Seizandō Shoten, 1998); Ryūshin Makino, Kitaemaebune no kenkyū [A study of kitamae ships] (Hōsei University Press, 1989); Hajime Komura, Kinsei Nihonkai kaiun to minatomachi no kenkyū [Studies of early-modern Sea of Japan marine transport and port towns] (Kokusho Kankōkai, 1992); Masaaki Murase, Kinsei Ise-wan kaiun-shi no kenkyū [Studies of the history of marine transport in early-modern Ise Bay] (Hōsei University Press, 1980); Yoshiyuki Saitō, Utsumibune to bakuhansei shijō no kaitai [Utsumi ships and the bakuhan market: A dissection] (Kashiwa Shobō, 1994); Masayuki Tsugawa, Kinsei Nihon kaiun no shomondai [Problems in marine transport in early-modern Japan] (Kansai University Press, 1998).

${ }^{2}$ This article is a rewriting of the conclusion of my book Kinsei Nihon kaiun-shi no kenkyu [Studies of the history of marine transport in early-modern Japan] (Yoshikawa Kōbunkan, 1994), and readers desirous of a more detailed empirical analysis are referred to that work. 
ers in farming villages, each of the groups engaging in their separate occupations, and this brought about social specialization and the need for mutual exchanges of goods and services.

On a nationwide scale, there were, on the one hand, the exchange markets of Osaka, with its character of consumption center, collection and distribution center, and processing center, and Edo, with its character of large consumption center, and on the other hand the regional districts, with their character of agricultural-product producing centers and handicraft consuming centers, and between these two types of communities there existed a routine distribution of commodities. On the regional district scale, there existed the castle towns and ordinary towns, with their character of being principally consumer centers, and the farming villages and rural districts, with their character of being principally producing centers, and between these two types of communities, too, there existed a distribution of commodities.

Thus in early-modern society several networks of commodity distribution, some large, some small, had been set up. Such a market structure assumed the distribution of commodities-obviously centering on the large population centers of Osaka and Edo, but also between centers all through the country. And what made it possible to carry out these distributions of commodities in large volumes and in smooth operations was the existence of the cargo vessels. This is where the cargo vessels, which were used as a means of transporting large volumes of goods, took on an important meaning under the Bakuhan system. Hence the development by Zuiken Kawamura (1617-99) of the western circuit route and the eastern circuit route and the appearance of the higaki (diamond-shaped latticework fence) and taru (barrel) cargo vessels were indispensable for the smooth maintenance of commodities distribution in the Bakuhan system, and the firm establishment of early-modern marine transport was inseparable from the firm establishment of the Bakuhan system. ${ }^{3}$ And the need for the cargo vessels went on increasing along with the further development of commodities distribution under the Bakuhan system.

${ }^{3}$ See Nobuo Watanabe, Bakuhan-sei kakuritsu-ki no shōhin ryūtsū [Commodities distribution at the time of the firm establishment of the Bakuhan system] (Kashiwa Shobō, 1966). The higaki and taru cargo vessels were two different types of vessels used in the regular runs between Osaka and Edo; the former got its name from the shape of the cypress or bamboo "fencing," or collars, around its sides to help prevent cargo from falling over the sides, and the latter from the barrels of sake that formed the ship's main cargo. 
Within the context of this kind of economic environment earlymodern cargo vessels sought to be economical in the way they were constructed. That is, because their sailing performance was improved so that it became possible to sail them even if they had a contrary wind or a side wind, and so that it became unnecessary to have crew members to man sculls, there was a large drop in the number of crew members required for each ship. As a result it became possible to sail a large cargo vessel with only a small crew. Thus, for example, only about fifteen men were needed to sail a sengokubune (a junk with a capacity to hold one thousand koku, or about 4,960 bushels, of rice). Furthermore, the crew members did not need to have the special qualifications or high level of navigational skills that would be required if the ship were a steamer; they acquired whatever skills they needed through repeated practical experience. While it is true that improvements in navigational skills were sought through the introduction of sea-lane charts and compasses, still, because the national seclusion policy made it unnecessary to sail over alien seas, ships' captains could manage coastal navigation just by keeping landmarks in sight: mountains, promontories, and the like.

One thing that was of vital importance was weather forecasting. This was closely linked with the structures of the cargo vessels. The reason was, the way early-modern cargo vessels were made, they were suitable for sailing in peaceful waters, and they were ill equipped to handle stormy seas. Their hulls had no watertight decks, their sterns were fragile, and they had oversized rudders. For this reason, sailing them in the Sea of Japan in the stormy winter weather was extremely difficult, and it was important to watch for weather forecasts that would guarantee the safety of the ships. This was also connected with the lack of speediness. Still, in the distribution of merchandise in the early-modern times, speediness was not that important a matter. What the early-modern cargo vessels were expected to provide, more than speediness, was a reliable and economical transport of large quantities of goods. The early-modern cargo vessels, therefore, can rightfully be described as ships endowed with an extremely early-modern economic rationalism as regards their manner of construction. As a result, whereas the narrowness of marine transport activities was responsible for the large variety of types of ships and the many different ways of constructing them that could be found throughout the 
country, when the distribution of merchandise took on a more important role and the territories covered by marine transport activities became larger, this variety was gradually given up in favor of the type of early-modern cargo vessel known as the bezaisen. ${ }^{4}$

If the significance of cargo vessels discussed up to this point is based on the economic environment and social conditions surrounding earlymodern cargo vessels and the economicalness of the way cargo vessels were constructed, then the second significance can be styled that of their functions.

Now, while early-modern cargo vessels were quite cheap compared to steamers, they were still expensive items in those days. For example, it cost more than one thousand ryō to construct a single sengokubune. Consequently, there would be only a limited number of entrepreneurs who could afford to put up that much money at one time, and in view of the danger of a shipwreck entailing the loss of such an enormous sum in one stroke, it becomes quite understandable why partnerships should make their appearance. And such joint operations could also be seen as a pioneering form of the company system. Joint financial backing took the form of cargo vessel subscription; losses and gains were calculated per voyage or per year; the apportionment of gains was determined on the basis of the percentage of the total money subscribed by each of the joint financial backers. The burden of sharing the new costs involved in repairs or in losses caused by accidents at sea and the like was also divided on the basis of subscription percentages. This sort of subscription in cargo vessel ownership has been noted as a form of cooperative business venture.

Again, when owners of cargo vessels came to own not just a single vessel but several, a new pattern emerged: instead of actually riding aboard the vessel and skippering it as the jikinori-sendō (direct skippers), owners began to hire okisendö (seafaring skippers) to sail the ships for them. I do not want to go into details here in regard to the extent of the okisendö's authority, but suffice it to say that the management of the individual ship was entrusted to the okisendo, and as a result there came about a division in functions between the owner of the ship (who in this situation was called an isendo (resident skipper) and the manager of the ship, the okisendō.

${ }^{4}$ Kenji Ishii, Zusetsu wasen shiwa [Illustrated story of the history of Japanese ships] (Shiseidō, 1983). 
A new pattern also emerged in regard to the form of managing the cargo vessels. There always was a difference between kaizumi (private carrier), in which the cargo was owned by the owner of the vessel and transported by him, and unchinzumi (common carrier), in which the cargo was owned by someone else, who paid the owner of the vessel to transport it for him; when such transport came to take on the character of regular runs, a division between the commercial functions and the transport functions resulted, and a more sophisticated version of the latter type of transaction came to be seen. Even though kaizumi was the basic form of cargo vessel management, the fact that cargo vessel management witnessed thiks kind of division between the commercial functions and the transport functions is, when considering the development of form of enterprise in Japan, something worth noting.

In addition, although the cargo vessel business was fraught with dangers such as calamities at sea, in those early-modern times there were no such things as insurance companies, and so a number of different schemes were used to cover such contingencies. One of them was the method mentioned already, of dividing up the costs of damages to ships caused by calamities at sea; another was a scheme by which all those who had cargo aboard a ship joined in making up for the loss of damaged cargo, even if their own cargo had not been damaged or lost. Other methods included avoiding the loading of all the cargo of any given cargo owner onto one ship (spreading a cargo owner's goods among two or more ships); the setting up of a reserve fund for emergencies, funded by cargo owners through a sort of levy on use of marine services; and simply paying extraordinary care to watch weather developments while actually out at sea. Thus, precisely because there existed no insurance system, owners and skippers devoted an inordinate amount of attention and effort to dividing the risks of loss, and in the area of cargo vessel management we find a function, and a form of enterprise, that cannot be overlooked by anyone thinking about the development of the modern company enterprise.

From what I have said above it should be clear that cargo vessels in the early-modern period of Japanese history were a means of transport that possessed an early-modern economic rationality from various aspects, whether that of the economic environment of the Bakuhan system (in the sense of having a secure means of trans- 
porting large volumes of goods on the basis of an underlying commodity distribution network), or that of the construction of the ships themselves, or that of the functions of the cargo vessels. This is why the construction of Japanese-style ships continued on into the Meiji Period and even into the Taishö Period, when modern means of transport would take over. This is where the significance of research on the history of early-modern marine transport lies. Having said this much by way of an introduction, I would next like to enter upon an examination of the specifics of the sort of thing early-modern marine transport with the above-mentioned functions was, and exactly what its economic rationality consisted in.

\section{TYPES OF CARGO VESSEL DEVELOPMENT}

Cargo vessels did not develop uniformly throughout the country in the early-modern period. They differed from place to place, depending on regional economies and the development of commodity distribution. It seemed to me, however, that the degree of development of cargo vessels in different parts of the country could be grasped in terms of the following four indices. The first would be an increase in the number of vessels; the second would be a move from reliance on transporting goods produced in one's own region by means of ships produced elsewhere to the promotion of production of ships in one's own region, then taking the further step of moving from transport of goods produced in one's own region to transporting goods produced in other regions-in other words, a change in the form of earning money by means of ships; the third would be the appearance of owners of several vessels (that is, a shift from jikinorisendo to okisend $\bar{o}$ ); and the fourth would be a move in the direction of large-scale operations, from small-scale cargo vessels to mediumscale to large-scale vessels. ${ }^{5}$

Using these four indices I did an analysis of 334 cargo vessels involved in sea disasters of one kind or another in the vicinity of Naoshima in Sanuki Province in the years $1687-1870 .{ }^{6}$ These are my findings.

${ }^{5}$ I categorize a vessel as small-scale if it has 1-3 crew members, as medium-scale if it has a crew of 4-9, and large-scale if it has 10 or more crew members.

${ }^{6}$ The data used were "ura tegata (nansen shōmeishō)" found in the Miyake documents 
First of all, the regions where there was the earliest development in cargo vessels were mainly located at the eastern end of the Inland Sea (places such as Osaka, Settsu, Kii, Sanuki), and it was for the most part in these places that more advanced forms of cargo vessel transport (making profits in other regions, the appearance of okisendō, and large-scale vessels) showed up at a comparatively early period.

Secondly, developments in cargo vessels would take place from the nineteenth century onwards mostly around the western end of the Inland Sea, in places like Suō, Aki, Iyo, and Bungo, and in these places I found an increase in the numbers of cargo vessels, a great improvement in ships made in their own regions, the appearance of okisendō, and a move to large-scale cargo vessels.

Thirdly, the regions where a certain amount of development in cargo vessels was evident toward the end of the Tokugawa Period were regions centered mostly in Hokuriku, San'in, and Kyūshū-for example, Hokkoku (the "northern provinces"), Izumo, Iwami, Nagato, Hyūga, and Satsuma; in these places they moved away from a reliance on ships made in other parts of Japan to promoting the construction of ships within their own provinces, and okisendo and medium-scale cargo vessels were also to be found.

Fourthly, there were regions where, even by the end of the Tokugawa Period, there was no conspicuous development in cargo vessels; these were the remote regions of Matsumae, Hizen, Higo, and Tosa, where some development in small-scale cargo vessels was to be found, but for the most part there was considerable reliance on cargo vessels from other parts of the country. ${ }^{7}$

A general idea can also be obtained from registers of the cargo vessels that entered ports on the island of Sado in the years 1725-1798. ${ }^{8}$ The reason is that most of the vessels registered there were cargo vessels from Kaga, Echizen, and other provinces in the Hokuriku area

of the Inland Sea History and Ethnology Archives (Setonaikai rekishi minzoku shiryōkan shozō Miyake monjo).

${ }^{7}$ Because of the limited availability of historical documents, my findings are slightly restricted in the regions and periods they cover. It would be a necessary future step, I believe, to validate and supplement these indices by getting a picture of cargo vessel trends in all parts of the country, including eastern Japan, and by going back even further in time.

${ }^{8}$ The data I used were "sho kaisen nyūshin tomechō" found in the Tsuchiya Sanjūrō Family archives. 
and from Settsu (Osaka), Sanuki (Shiwaku), Satsuma, and other regions at the eastern end of the Inland Sea. Also, some information can be had in regard to the size of vessels, and places that had cargo vessels with crews of only two or three men came from Kaga, Echigo, Sado, Etchū, Noto, Ugo, and Tango, all regions in the Hokuriku area or nearby. Still, these regions did not have only small vessels; they also had medium-scale vessels with 4 to 9 crew members, and if anything, most of their vessels were of the medium-scale variety. Now, when you look at the regions that had mostly medium-scale vessels, you find that Kaga had 209, Echizen had 64, Etchū had 37, Tsugaru had 10, Sado had 8, and Noto had 5. The fleets of Kaga, Echizen, and Etchū in particular were made up of a high percentage of medium-sized cargo vessels, at $92 \%, 78 \%$, and $74 \%$, respectively. These regions were the regions in the Hokuriku area that were relatively advanced in cargo vessel development, and they also had some large-scale vessels. The regions that owned mostly large-scale vessels were Osaka with 46, Harima with 43, Settsu with 36, Izumi with 24, Shiwaku (Sanuki) with 41 , and Bizen with 15 , which meant that $88 \%$ of Osaka's fleet was composed of large-scale vessels, $98 \%$ of Harima's, $97 \%$ of Settsu's, $89 \%$ of Izumi's, and $100 \%$ of Shiwaku's and Bizen's. Sometimes the cargo vessels were especially large, requiring crews of fifteen or more; such vessels tended to be owned by regions at the eastern end of the Inland Sea, such as Settsu, Osaka, Harima, Shiwaku, Bizen, and Izumi. The actual count was Settsu, 24; Osaka, 14; Harima, 14; Shiwaku, 14; Izumi, 5; Ugo, 4; Suō, 4; Sanuki, 4; Hizen, 3; and scattered holdings of 2 or 1 .

\section{CARGO VESSELS AND COMMODITY DISTRIBUTION}

Because of the fact that Bakuhan society was one whose economic base was the kokudaka system, conversion of the annual payments of rice tax into cash became a necessity, and for the same reason rice was the most important commodity. This was also apparent from the fact that far and away the commonest commodity, making up nearly $50 \%$ of all goods handled at ports throughout the country (in places like Osaka, Akita, Niigata, Izumo, Iwami, Aki, and Awa) and carried on ships as cargo, was rice. Thus, for example, in 1714 rice accounted for $49.0 \%$ of the total cash value of all the goods imported into 
Osaka; in second place was rapeseed, at $6.1 \%$, so one gets some indication of the huge gap between the volume of rice handled and other products, and of the extent to which rice dominated the market. $^{9}$

The main transporters of jomai, the annual payments of rice tax to the Bakufu, between 1688 and 1735 were the cargo vessels from Shiwaku in the province of Sanuki; after 1735 Osaka cargo vessels gradually muscled in, so that from 1751 to 1763 they became the main transporters, with vessels from other parts of the Inland Sea transporting the rest, and Shiwaku vessels withdrew from the trade altogether. In 1830-43 Settsu (especially Nada cargo vessels from Mikage and other ports) and Inland Sea regions (especially cargo vessels from Suō, Iyo, etc.) made conspicuous inroads into the business, while Osaka ships faded from the picture. Even in the case of Iwami jomai transport, the main transporters from 1841 on changed from Osaka cargo vessels to Nada cargo vessels from Mikage, Ōishi, Imazu, and other places in Settsu. All of the above related, however, only to the large-scale cargo vessels involved in the transport of jomai to Edo; the situation was different in regard to ships transporting jomai bound for Osaka.

In the case of ships transporting Osaka-bound jomai, it was quite possible to make the voyage in medium-scale cargo vessels as well, so from 1841 medium-scale cargo vessels from the San'in and Hokuriku areas began taking over as the mainstays from ships from the Osaka region and the Inland Sea. Also, in the case of jomai transport from Echigo province, most of the ships carrying Edo-bound jomai via the eastern circuit were cargo vessels from eastern provinces such as Edo, Uraga, Nagoya, and Ishinomaki. This was markedly different from the ships carrying jömai to Edo or Osaka via the western circuit; these latter were mainly from places like Settsu, Iyo, or Aki within the Osaka or Inland Sea areas. In other words, the Edo-bound fleets taking the eastern circuit were made up of cargo vessels from that region constructed in such a way that they were best adapted to sail the eastern circuit. Another thing: whereas ships carrying Edo-bound jömai were large-scale cargo vessels of the thousand-koku class, ships carrying jomai to Osaka also included medium-scale vessels that could only carry up

\footnotetext{
"Susumu Nagano, "Bakuhan taisei chūki no shijō kōzō ni tsuite no oboegaki" [A note on the market structure in the middle years of the Bakuhan system], in Ösaka no kenky $\bar{u}$ [Studies of Osaka], ed. Mataji Miyamoto, vol. 3, p. 372 (Seibundō Shuppan, 1969).
} 
to $500 k o k u$. Furthermore, the registers of jomai-bearing vessels that entered ports in the Owase region of Kishū indicate that most of the vessels were from Settsu, Kii, and Aki, but of these, those from Osaka (i.e., Settsu) predominated. Towards the end of the Tokugawa Period, however, the cargo vessels from Osaka slightly lost ground, and we find Nada cargo vessels putting in a strong appearance.

Besides rice, other goods that were transported included sake from the Nada region (present-day Kobe), mandarin oranges, lumber, and charcoal from the Kishū region (present-day Wakayama Prefecture), salt from the Akō region (in present-day Hyōgo Prefecture), indigo and salt from Awa (present-day Tokushima Prefecture)there was, in other words, a clear trend toward shipping specialties from certain regions. Now, regional specialties increase in value the farther removed their destination is from the producing region, and this is where we can see the importance of the role that cargo vessels played. Let us look more closely at the transport of these regional specialties.

Nada sake was transported to Edo by means of taru cargo vessels, and most of these taru cargo vessels were from Osaka, Nishinomiya, and Nada, or from Kishū. The former group of cargo vessels were hired as charter vessels from taru cargo vessel wholesalers based at Denbō in Osaka, or from Nishinomiya taru cargo vessel wholesalers. Kishū cargo vessels, on the other hand, were made up of vessels from three bays in the Kishū area: Hidaka, Hii, and Tonda; up to about 1804-17 they were at the height of their prosperity, then gradually started losing ground around 1818-43; in 1833 the ship owners finally moved away from taru cargo vessels and threw their lot in with higaki cargo vessels. In contrast to the dwindling fortunes of the cargo vessels from Kishū, which were the backbone of the taru cargo vessel fleet, the cargo vessels from Nada rose to prominence around this time, and at the end of the Tokugawa Period it was that region's vessels that would form the core of the taru cargo vessel fleet. ${ }^{10}$

Seventy percent of the mandarin oranges from Arida in Kishū were shipped to Edo, $20 \%$ to Owari (present-day Nagoya region), and $10 \%$ to Ise and Uraga. Vessels from Hidaka in Kishū made up nearly $80 \%$ of the ships transporting mandarin oranges around 1772-1800,

\footnotetext{
${ }^{10}$ Masahiro Uemura, "Taru kaisen no tokushitsu" [The special characteristics of taru cargo vessels], in Nihon suijō kōtsü-shi ronshü (see note 1 above), volume 6 .
} 
but after that their stranglehold gradually began to loosen. By 1818-29 they carried less than $50 \%$ of the mandarins, and by 1848-53 they had all but disappeared from the scene. In their place cargo vessels from Awaji Island, from Ōkawa, Susami, and Wakayama in Kishū, and from Utsumi in Owari formed the backbone of the fleet transporting mandarins. Lumber and charcoal from Kumano in Kishū were shipped to Edo and Osaka by means of cargo vessels from Shingū and Udono located at the mouth of the Kumano River. Particularly noteworthy is the fact that charcoal from the Shingu domain were sometimes shipped to Edo by means of vessels owned by the lord of the domain, the Mizuno family.

In the case of Ako salt, approximately $75 \%$ was transported to the Edo area; towards the end of the Tokugawa Period it was shipped in roughly a 50-50 ratio by ships from Akō and ships from other regions such as Edo, Uraga, and Kishū, but in the early Meiji Period the percentage handled by ships from the Akō region began increasing. Within the Akō region itself, it was vessels from Sakoshi Bay that made the most conspicuous inroads.

Salt from Awa was transported, along with shipments of indigo, in large-scale cargo vessels from Hitachi, Edo, Sagami, Izu, Ise, Kii, Nagato, and Awa to Edo. The influx of fish fertilizer from the northern provinces to Awa was carried mostly in large-scale cargo vessels from Matsumae, Echizen, Etchū, Echigo, Noto, Kaga, Izumi, Hyōgo, Suō, and Awa. Furthermore, the shipment of rice to Awa was handled mostly by relatively small-scale cargo vessels from Owari, Harima, Awaji, Sanuki, Iyo, Bizen, Bitchū, Bingo, and Awa. In other words, we can say in general that salt, indigo, and fish fertilizer were transported by means of large-scale cargo vessels from Edo and the northern provinces, while rice was transported by means of small-scale cargo vessels from Osaka and Kyūshū.

\section{THE PERFORMANCE OF CARGO VESSELS}

While the transport of large volumes and safety were demanded of early-modern cargo vessels by the economic community that formed the basis for their existence, speed was not of vital importance. From the nature of their construction, cargo vessels were largely at the mercy of natural conditions like the seasons of the year and the weather of 
the day. Thus, no voyages were made in winter to regions on the Sea of Japan side of the country, ${ }^{11}$ and sailing out to sea was avoided on days of rainy weather or strong winds. As a result, the length of time needed to complete a voyage often was dragged out.

In the case of jomai shipment from Echigo, it took about one month and a half for an empty ship to sail from Edo to Echigo via the eastern circuit route, and this was roughly approximated the amount of time it took to go from Osaka to Echigo.

In the case of shipment of jomai from Iwami Province, a cargo vessel setting sail from Osaka in January or February was expected to take eight days to reach the loading port in Iwami, but in reality it might take from twenty days to over a month to get there, arriving sometime in March. Port entry times were between 9 a.m. and 5 p.m., but the early afternoon was the busiest time, with very few arrivals registered during the night or early in the mornings. Once in port, ships stayed from four to nine days. The reason for long layovers was mostly a westerly wind, rainy weather, or high seas, but cloudy weather was also a frequent reason. The vessels set sail from the loading ports between 5 a.m. and 5 p.m., with two peaks in the very early morning and in the early afternoon. But it was not uncommon for vessels that had set sail from a port to return to it; approximately two-thirds of the cargo vessels experienced one or two returns to port. The hours from 5 p.m. to 7 p.m. were when most vessels returned to port, which means that weather conditions had taken a turn for the worse in the late afternoon and the vessels' skippers were taking no chances.

In the case of jommai cargo vessels that made port in Owase in Kishū, the skippers would first receive their papers at Kawaguchi in Osaka, then set sail, unladen, for their loading ports, with the peak season being from November to February. The vessels that set sail in November of December carried jömai from the Kyūshū and Inland Sea regions, while transport on the Sea of Japan side of the country was difficult in winter, so it was put off until the following year. At the load-

${ }^{11}$ This applied only to long-distance voyages undertaken by the large-scale cargo vessels. Short-distance voyages by smaller cargo vessels, of course, were undertaken as weather conditions permitted. See Yoshiyuki Saitō, "Ryūtsū seiryoku no kōtai to shijō kōzō no hen'yō" [Changes of the guard in distribution power and shifts in market structure], Atarashii kinse-shi [New early-modern history] (Shinjinbutsu Ōraisha, 1996), p. 49. 
ing ports a layover of from one to two weeks was necessary for the vessels to take on the jomai and because of weather deterioration. Then, from the loading ports to Owase it took about one week from Settsu, about two to four weeks from Harima, Bizen, or Bungo, about two months from Echigo, and more than two months from Dewa. Long layovers in Owase of two weeks or more were common. By far the most frequent cause was rainy weather; headwinds on the way to Edo were also given as a reason. The times at which ships most frequently entered Owase were between 1 and 3 p.m., and the most frequent times of departure were in the morning between 5 and 7 .

In the case of taru cargo vessels, the fewest number of days needed to make the trip from Imazu in Settsu to Edo in the late Tokugawa Period was ten days, and the longest trip took a full 73 days, so the average was from two weeks to one month. When steamers came in, the trip could be made in just a few days, but Western-style sailing ships did not do much better than the taru cargo vessels, managing one roundtrip every one or two months.

Cargo vessels from Akō could make the roundtrip from Akō to Edo and back three or four times a year, and even though this would increase slightly to four to six times a year in the early Meiji Period, it still meant they were only managing one roundtrip every two or three months. Cargo vessels from Awa also engaged in transporting salt, indigo, and fish fertilizer to Edo and other places four to five times a year. Even Kishū cargo vessels only managed four or five roundtrips to Edo and other places to transport higaki (diamond-shaped latticework fences) cargo, mandarin oranges, salt, and so on. In comparison, cargo vessels from Shingū transported Kumano charcoal from Shingū to Edo in fifteen days, for which they received a prize, and they also received a reward for making seven roundtrips a year between Edo and Shingū.

Even though the early-modern cargo vessels made economical sailing trips and paid what attention they could to safety measures such as waiting for good weather, they still sometimes met with disaster at sea simply by reason of the fact that marine transport was so unpredictable. Kishū's Arida mandarin oranges, for example, were transported in from 50 to 70 cargo vessels a year, of which about three a year were regularly to meet disaster at sea, for a disaster rate of approximately $5 \%$ a year. In the case of taru cargo vessels, every year 
from one to four ships leaving Uozaki in Settsu met with disaster; since from 150 to 200 cargo vessels a year were involved, this represented an accident rate of about 1 to $2 \%$. Of the 55 ships that left Imazu in Settsu in 1866, four (7\%) were involved in accidents, and seven $(5 \%)$ out of 135 ships in 1868, so the disaster rate for this port was slightly higher than in the case of Uozaki.

\section{PROFITS AND LOSSES AND FREIGHT RATES}

We have clear pictures of the costs involved in operating some individual cargo vessels in early-modern times: the Isemaru, Tokuichimaru, Köfukumaru, and Tokuzenmaru from Awa, the Ekikyūmaru and Ryüjinmaru from Kishū, and the Rikichimaru and Chōanmaru from Akō. We know how much some of these ships cost: Isemaru (cargo capacity: 1,100 $k o k u), 1769$ ryō plus (including 300 ryō for load purchase funds); Tokuichimaru (capacity: 700-800 koku), 60 kan 337 momme plus; Köfukumaru (capacity: 320 koku), 642 ryō plus; Tokuzenmaru (capacity: 1,400 koku), 1537 ryō plus; Ryūjinmaru (capacity: 1,500 koku), 104 kan 489 momme plus. Thus, except for the small-scale Köfukumaru, the "one thousand koku" vessels all required more than 1,000 ryo each. ${ }^{12}$

The Isemaru made 21 voyages in a period of four years and some months, for an average profit per voyage of over 56 ryō, versus operating costs of more than 52 ryōa year. Consequently, if operations had gone smoothly without any accidents or the like, it would have had an annual profit of 200 to 300 ryō per year. But it did incur large losses from having to pay for construction and repairs and from having cargo washed overboard in storms, so that eventually it ended up with a loss of 1,420 ryō, $20 \mathrm{kan}$, and 268 momme plus. The Tokuichimaru was operated for seven years without any repairs or accidents. Operating.

${ }^{12} \mathrm{~A}$ ryō was a gold coin (also called a koban) that varied in value; in 1609 one ryō was officially made equivalent to 50 momme of silver, but this was only a rough standard, and at the end of the seventeenth century it varied considerably in value. A kan was a measurement of weight equaling 3.75 kilograms of silver; in the early-modern period it started out equivalent to 1,000 zeni, or coins of brass, copper, or iron with square holes in the center. A momme was a measurement of weight equalling 3.75 grams of silver (so 1 kan equaled one thousand momme), and then the equivalent of 1 zeni in the early-modern period. The amount of gold in the ryo was constantly being decreased, and of course so was its value in silver. As of 1862 , one $r y \bar{o}$ was considered equivalent to 1.25 Mexican silver dollars. 
costs were 1,865 ryō, 5 kan, 589 momme plus for the seven years, for an average of 279 ryō plus per year, but because it suffered no disasters at sea it brought its owner a profit of close to 1,500 ryō, or a yearly average of more than 212 ryō. Hence the initial investment in Tokuichimaru of approximately 1,000 ryō had been completely recovered in five years, after which it brought in an annual clear profit of around $200 r y \bar{o}$, and the vessel itself was equivalent to cash on hand. The Köfukumaru, being a small-scale ship, over four years finished with over 122 ryō in operating costs per year, less than half the operating costs of Tokuichimaru, but it brought in profits of only 15 ryō 76 momme plus over the four years; even though a profit of 148 ryō was made on the sale of the ship, when you take into account the more than 667 ryō it cost to build and outfit the ship, it ended up representing a loss of over 502 ryō.

The Tokuzenmaru, on the other hand, made 16 voyages in four years, at a cost of 887 ryō, 79 momme plus, for a net profit of 615 ryō, 109 momme plus. The Ekikyūmaru made 17 voyages in a little over three years, with a profit of 3 kan per voyage. The Ryüjinmaru made 12 voyages in two years plus; it had earnings from freight charges of 7 kan per voyage, but costs of 5 kan, for a profit of 2 kan per voyage. When all the other payments for the year are subtracted, the ship is left with a net profit of only 8 kan per year. The ship itself, however, cost 104 kan, 489 momme plus, and 11 kan, 700 momme were spent on masts; in the end what was left as assets were $9 \mathrm{kan}, 113$ momme plus and 780 momme from selling the old masts. The Rikichimaru made 18 voyages over six years, generating an income of $90 \mathrm{kan}, 668$ momme plus, or a profit of 15 kan, 111 momme plus per year (over 5 kan per voyage). The Chöanmaru made 41 voyages over 13 years, with an income of 5,566 ryō plus and 4 kan, 659 momme, or 130-140 ryō per voyage. But repairs and other costs over the same period came to 2,465 ryō, 1 kan, 733 momme plus, so that in the end the profit was 3,100 ryō, 2 kan, 925 momme plus, for an average annual profit of over 238 ryō.

Freight charges for transporting Echigo jömai to Edo, for example, were (in 1848) 20 ryō, $2 b u$ (one $b u$ was one-fourth of a $r y \bar{o}$ ) per $100 k o k u$ of rice from Niigata via the western-circuit route, but 23 ryo, $1 b u$ via the eastern-circuit route. The latter route's higher cost reflected the higher degree of risk involved and the greater speediness of delivery. The transport of jömai from Iwami to Edo or Osaka 
was, in the period 1809-59, from 900 momme to 1 kan per $100 k o k u$ to Edo, and 550-600 momme to Osaka; thus the latter freight charge was roughly six-tenths that of the former. The charge for transporting Nada sake to Edo in the years 1825-33 was 1 kan per 100 koku, whereas the freight charge for $100 \mathrm{koku}$ of rice was only 730-795 momme, thus sake cost 20 to $30 \%$ more to ship. As we get closer to the end of the Tokugawa Period, however, freight charges for sake tend to be kept down relative to charges for rice. In the transport of Arida mandarins to Edo, the freight charge for a basket of mandarins priced about 4 momme was 1 momme, so that the freight charge was one-fourth the price of the commodity.

\section{FORMS OF MANAGING THE CARGO VESSELS}

In this section I would like to look at the forms taken in management of the cargo vessels, making use of the information that is available on Awa, Kishū, Akō, and Nada cargo vessels.

The first case we can look at is the Yamanishi family, Awa wholesalers dealing in salt and fertilizer. This family used the Isemaru as a private-carrier vessel to send a shipload of salt that it had purchased to Edo from Awa (present-day Tokushima Prefecture) and to bring back to Awa fertilizer taken on in Edo, while transporting en route loads of indigo, rice, wheat, sugar, and so on. Except for a few things like aidama (indigo plants processed into a paste and hardened into round balls) that altogether made up only a small fraction of the total cargo, the ship's cargo was owned by the Yamanishi family. A breakdown of the cargo carried by the Tokuichimaru shows that it carried 24 loads of fish fertilizer, 2 of kelp, 8 of salt, 2 of rice, 3 of sugar, and 9 of miscellaneous other items; of these, 33 loads were kaizumi, or private carrier, and so owned by the Yamanishi family, while 15 were unchinzumi, or common carrier, and so somebody else owned it and paid the Yamanishi family to transport it for them. All the salt, sugar, rice, and rapeseed were kaizumi, as was two-thirds of the fish fertilizer; the kelp and soybeans were a mixture of kaizumi and unchinzumi, while tobacco leaves were nearly all unchinzumi. Consequently, the income gained from unchinzumi did not exceed one-tenth of the total; the lion's share of the profits-despite the occasional loss of some cargowere derived from kaizumi. In short, the Tokuichimaru was managed 
as a "northern provinces ship" to transport mostly the Yamanishis' own cargoes of salt and fish fertilizer, and the bulk of the profits were derived from its function as a private-carrier vessel.

The Tokuzenmaru carried 6 loads of fish fertilizer, 6 of aidama, 16 of salt, 2 of rice, and 5 of miscellaneous items, and of these 35 loads 23 were private carrier, and the rest common carrier. The fish fertilizer was mainly private carrier, with a minor amount of it freight; the private carrier portion was fish fertilizer that had been sold exclusively to the Yamanishi family. All of the aidama loads were common carrier; it seems they were taken on as extra cargo to be sent to Edo along with the Saidajio (Saida salt) that the Yamanishi family had purchased. In all of the salt loads it is believed that Saida salt owned by the Yamanishis was transported, but at times they also bought Takuma salt, Akō salt, and "new Saida salt" from Sakaide in Sanuki. Thus the Tokuzenmaru was managed in such a way as to have private carrier cargoes of salt the mainstay of operations, and these were complemented by common carrier cargoes of aidama and a mixture of private and common carrier cargoes of fish fertilizer. Ninety percent of the total profits were derived from shipping salt, with the remaining ten percent coming from fish fertilizer, aidama, and rice. Even though there were considerable fluctuations in the profits gained from private carrier of salt, when the profits were high it was possible to take in more than 100 ryō on one voyage, so one can get some idea of the size of the profit that could be gained from private carrier. Money was lost on three of the private carrier loads, but (in the case of Tokuzenmaru, at least) the amount lost per load was not much, and this did not diminish much the overall fine results from cargo vessel operations.

Thus the management of cargo vessels by the Yamanishi family could be described as the management of purchased-cargo vessels that basically carried their own cargoes, consisting mostly of salt, fish fertilizer, and rice, and, with a view to more efficient use of the vessels, also common carrier cargoes of aidama and other commodities. So it seems the reason the Yamanishi family went into cargo vessel management was to extend their business operations beyond those of being salt wholesalers and fish fertilizer wholesalers and, by acquiring their own cargo vessels, to be able to carry their own goods as private carrier and then sell the in the most advantageous way. Not content to make a profit from simple cargo-vessel management (that is, from freight 
charges obtained by transporting other people's goods), they took the risks involved in private carrier (that is, transporting their own goods) and chose the form of management-private carrier-that was linked with more profitable sales of their own goods. This was the more rational approach to cargo-vessel management as far as the Yamanishi family was concerned, given their access, as wholesalers, to the selling of salt and fish fertilizer.

Now let us look at the Kishū cargo vessels, beginning with the case of the Ryüjinmaru, owned by the Murakami family. It carried only common carrier cargoes of sake, salt, aidama, and so on. On each of its voyages it earned an income of 5 to $9 \mathrm{kan}$. But it cost around $5 \mathrm{kan}$ to operate each voyage, so that the profit per voyage gained from common carrier was around 2-3 kan, which makes one wonder about the soundness of running a freight-cargo operation. Still, freight-cargo operations are fine as long as large volumes of stably priced commodities can be transported continuously throughout the year, but they are not as suited as purchased-cargo operations when you have commodities whose prices fluctuate wildly or which suffer seasonal fluctuations. In the case of the Ekikyümaru, owned by the Sono family, 10 of its 17 voyages were common carrier cargoes of mandarin oranges. Now, the shipping of mandarins has a seasonal nature, and it takes place only from October to the following January. As long as the Kishū cargo vessels were of the taru variety, they could fill in the intervening months by transporting sake, but once the Kishū owners switched to higaki cargo vessels in 1833, they had to find something else to transport to fill in the non-mandarin months. The salt that they came up with as a possible cargo was to be private carrier, and the direction to take to break the limitations of the Kishū vessels as strictly freightcargo vessels was private carrier. This foray in to private carrier, which always entails the risk of loss, would destroy the stability of Kishū cargo vessels, however. Their private carrier would consist only of salt and soybeans, whereas the candles, sugar, specialties, and official government baggage were common carrier cargoes taken on along with the mandarin oranges; quantity-wise it did not amount to much, but for the trips to Osaka there also were common carrier cargoes of fish fertilizer. Furthermore, shipment of soybeans produced losses derived from private carrier, but private carrier cargoes of Akō salt produced the highest profits in the 17 voyages-showing what a spec- 
ulative risk private carrier could be. The Kishū cargo vessels were, therefore, managed principally as freight-cargo operations (a fact that is also clear from their being made up of taru and higaki vessels), but they had to engage in purchased-cargo operations of shipping salt, etc., because of the lack of year-round cargo loads, and this showed the existence of limitations in freight-cargo transport in early-modern cargo vessel management.

In the case of the Akō cargo vessel, the Rikichimaru owned by the Okutō family, all 18 of its voyages involved the shipment of salt on a private carrier basis, with supplementary private carrier cargoes of dried sardine mash (used for fertilizer) and dried bonito and supplementary common carrier cargoes of rice, tatami matting, dried sardine mash, barrels, etc. All the salt was purchased from the Akō castle towns and sold mostly to salt wholesalers in Edo but also to buyers in Kanagawa, Shimoda, Toba, and Kumano. The income from one voyage could range from a profit as high as 14 kan, 333 momme plus, down to a loss of $4 \mathrm{kan}, 123$ momme plus; the average income was a profit of 5 kan plus, however, so the owners made a considerable amount of profit from private carrier salt. Chöanmaru had 41 voyages, of which 38 involved the transport of private carrier salt, with supplementary common carrier rice, lumber, charcoal, cotton, etc. The salt was bought from Akō wholesalers, and this was sold almost exclusively to salt wholesalers in Edo.

The three voyages in which salt was not the main cargo, rice was, and in all cases the rice was common carrier. Since private carrier salt was the main cargo and the supplementary items were insignificant amounts of common carrier, the income from a single voyage varied from a high of 667 ryō plus in profit all the way down to a loss of 227 ryō plus; with an average profit of 130-140 ryō per voyage, however, it can be seen what a great amount of profit could be obtained from private carrier salt. In this way the owners of Akō cargo vessels carried out a form of management that made private carrier of their local Akō salt their staple cargo, and it proved to be a very profitable mode of selling their local specialty and a rational way of managing the vessels.

When we look at the cargo vessels from Nada engaged in transporting Nada sake, we find that the producers of Nada sake were keen to own cargo vessels, with the result that, by the end of the Tokugawa Period, nearly all of the taru cargo vessels were in the hands of Nada own- 
ers. But the shipping of sake in their own vessels then created a sort of problem. Originally, even though sake producers had their own vessels, the system agreed upon was that they had to charter other ships from a taru cargo vessel wholesaler, and they could not load their own merchandise on board their own ships. In actual practice, however, sake producers were giving preferential loading to their own merchandise on their own ships. In the case of a vessel owned by the Akōya sake producer in the village of Uozaki, for example, $75 \%$ of the cargo going out from Uozaki was that of the owner's near kin; this amount was more than the slightly less than $50 \%$ ratio of their cargo on "neutral" ships. In the same way, on vessels owned by the Yamaji family, more than $40 \%$ of the cargo was that of the Yamaji family members; this showed a decided preference for their own vessels over "neutral" vessels, to which they consigned less than $10 \%$ of their cargo.

Consequently, despite the prohibition against freely loading one's own merchandise on one's own ships, the preferential shipment of same-family cargo on one's own ships was considered one very good reason for sake producers to own their own vessels. As far as the sake producers, desirous of expanding the scale of their sake production operations, were concerned, guaranteeing means of transport at peak times of sake transport served to increase the advantageousness of selling sake in a way that would cope with the fluctuations of sake prices in Edo and the changing conditions concerning entry in to that port.

\section{CARGO VESSELS AND SPREADING OUT THE RISKS}

Early-modern cargo vessels were, by reason of their construction, greatly at the mercy of natural conditions. In spite of the fact that their skippers sacrificed speed for safety and kept a wary eye out for dangerous weather, the ships had an accident rate of around 5\%. For this reason, given the nonexistence of insurance schemes in early-modern society, a number of devices were used in order to spread the risks involved in cargo vessel operations.

While the Japanese sailing vessels were far cheaper than steamships, they still cost up to more than one thousand ryō, a princely sum in those days. Consequently, there were only a limited number of entrepreneurs who could afford to put up that much money at one time, and in view of the danger of a shipwreck entailing the 
loss of an enormous sum of money in a matter of seconds, it is quite understandable why partnerships should be entered into. Joint financial backing took the form of cargo vessel subscription; losses and gains were calculated per voyage or per year; the apportionment of gains was determined on the basis of the percentage of the total money subscribed by each of the joint financial backers. The burden of sharing the new costs involved in repairs or in losses caused by accidents at sea and the like was also divided on the basis of subscription percentages.

Let us look at the cargo vessels from Awa, beginning with the Isemaru. The ship was financed on a 50-50 basis by the indigo merchant family of Yokichirō Miki and the salt wholesaler family of Shōgorō Yamanishi, with management of the vessel entrusted to the Yamanishi family. The vessel was a rebuilt version of a cargo vessel earlier active under the name Sumiyoshimaru; the costs involved in rebuilding the vessel $(1,769.625$ ryōand 3.69 momme) were borne equally by both families. Additional costs in subsequent years, likewise borne equally by both families, were: 85.75 ryō and 10.65 momme in 1845 for changing masts; 55 ryō and 6.28 momme for repairing masts in 1847; 379.5 ryo and $20 \mathrm{kan}, 457.11$ momme for major overhauling, also in 1847; and 504.125 ryō and 9.57 momme in losses from cargo washed overboard during a shipwreck in 1849. A settling of accounts was made after each completed voyage, and the profits divided equally.

The expenses for the Tokuichimaru, on the other hand, were at first met solely by the Yamanishi family, but in 1855 the Yamanishi family and the skipper, Hikojirō Nakaya joined in a 50-50 sharing arrangement. Three years later the Yamanishi family returned to Nakaya his portion of the investment and once again took over sole ownership. The Kōfukumaru was invested in jointly, on a 50-50 basis, by the Yamanishi family and a person named Chūzaburō from the Okazaki Jukkenya, but the management of the ship's operations was left to the Yamanishi family.

Among the Kishū cargo vessels we find similar arrangements. In the case of those from Hii, shared ownership was frequent, especially by sake producers, and this was one of the reasons for the refusal of Kishū owners to merge their taru cargo vessels with the higaki cargo vessels. Ryūjinmaru, for example, was $24 \%$ owned by Buhei Suzuya. Thus, while it cannot be denied that shared ownership in a cargo vessel was not merely a matter of the need for huge amounts of money 
or the functions of apportioning profits and dividing up risks, but that also involved were such things as preferential treatment for an owner's cargo and the preservation of customers' trust, it is something that is noteworthy as one form of joint enterprise.

Furthermore, in the management of cargo vessels a variety of devices were used to make up for the absence of any insurance schemes despite the danger of such things as shipwrecks. Joint investment in a vessel was one such device to spread risk, and there were several others as well. Different ways of spreading cargo among vessels were also used, so that a given merchant's goods were not all loaded onto one vessel.

In the transporting of Arida mandarins from Kishū, Edo mandarin wholesalers were not linked with the tsumiai (organization) that formed a unit for the purposes of determining how much cargo was to be loaded onto one vessel, but with the kumikabu, a producers organization, five of which joined to form one tsumiai. As a result, even if a vessel were to meet with disaster at sea, an individual Edo mandarin wholesaler would only bear one-fifth of the losses incurred. Similarly, in the transport of Iwami jomai, the rice that was brought in from the various villages was.not collected in a single storehouse but divided up and stored in different storehouses, and when it came time to load the rice onto cargo vessels, all the rice kept in one storehouse was not loaded onto one and the same vessel but divided up among several vessels.

Nada sake was treated the same way: all the sake produced at one center was not loaded onto one and the same vessel but divided among several vessels, and any one vessel carried allotments of sake produced from several different producing centers. And cargo from one center but owned by several different owners was also divided among several different vessels, so that one merchant's cargo was never all loaded onto one vessel but divided among several vessels. All this was done in order to spread the risks to cargo owners stemming from the possibility of shipwreck, etc.

And finally, as I mentioned earlier, extraordinary attention was paid to the weather before and during the sea voyages. The very fact that no insurance schemes existed made all such painstaking efforts and care to ensure that risks were minimized a necessary fact of life. And, when despite all such precautions a disaster did strike at sea, a 
scheme was in place for rescue at sea so that cargo could be unloaded, owners notified, water-damaged cargo disposed of, and similar measures taken as speedily as possible.

\section{THE MODERNIZATION OF CARGO VESSELS}

The introduction of Western-style sailing ships and steamships would have to be considered the modernization of early-modern cargo vessels. Taru cargo vessels and sake were closely linked ever since the first taru vessels were built, but Western-style sailing ships and steamships were introduced comparatively early in the transport of sake.

The first use of a steamship in the transport of sake from Uozaki was in September 1871. The Japanese-style taru cargo vessels carried $95 \%$ of the sake transported in that year, $77 \%$ of what was transported in 1872 , and $67 \%$ of the sake cargo in 1874 , but by 1878 their share dropped to $30 \%$, and by 1879 taru cargo vessels had disappeared from the scene. The sharp drop in the use of Japanese cargo vessels as a means of transporting sake began in 1877, and in two years they were history. The first Western-style sailing ship appeared on the scene in November 1873, two years after the advent of the steamship. Only one Western-style sailing ship was in use in 1874 , but by 1878 there were 34 , and they carried $30 \%$ of the sake cargoes; in 1879 the figure stood at 74 ships carrying $59 \%$ of the sake. These sailing ships rapidly increased in numbers and took the place of Japanese-style vessels.

Steamship numbers came to a mere 8 in 1871, and these 8 handled only $5 \%$ of the sake transported from Uozaki. But they went on steadily increasing, if not in numbers, then certainly in the percentage of sake cargo they transported: in 1872,18 ships carried $11 \%$ of the sake; in 1873, 45 ships carried $23 \%$; in 1874, 70 ships carried $33 \%$; in 1878,41 ships carried $35 \%$; and in 1879,52 ships carried $41 \%$.

A similar phenomenon occurred in the transport of sake from Imazu. In 1869 there were no steamships or Western-style sailing ships in use, and all the sake was transported by Japanese taru cargo vessels, but by 1882 the Japanese vessels had all disappeared, and Western-style sailing ships (73, carrying $66 \%$ of the cargo) and steamships (38, carrying $34 \%$ ) had taken over completely.

Thus the business of transporting sake from the Nada district to Tokyo saw a sudden switch occur in the period 1871-79, from Japan- 
ese-style cargo vessels to steamships and Western-style sailing ships. The reason for this switch was that, to transport Nada sake, which was a cargo that suited regular voyages between the Osaka-Kyoto area and Tokyo, it was more economical to introduce the Western sailing ships and steamships than to keep on relying on the Japanese taru vessels.

Still, the Western-style sailing ships and steamships were expensive, and upkeep expenses such as fuel, insurance, repairs, depreciation, etc., and the costs of employing crew members with high technical skills were far greater than for Japanese vessels, so even though these ships were better than Japanese vessels in loading capacity, speediness, and safety, the latter were not at such a disadvantage when it came to sailing along the Japanese coastlines. Instead of fading from the scene completely, they managed, depending on the merchandise and the sea-lanes involved, to survive even into the Meiji Period on the basis of their early-modern economic rationality. The kitamaebune were a good example of this. ${ }^{13}$ As a result, in general even in the early Meiji period, or even up to the Taishō Period, Japanese vessels were still plying Japan's coastal waters.

Akō cargo vessels were still active in carrying Akō salt to the Tokyo area up to around 1905. The vessels used, however, were not the earlymodern versions, but improved models. Thus, while a ship used to make an average of three voyages per year in the Tokugawa Period, in the Meiji period it was averaging 4 or 5 voyages; some were even averaging as many as 7 or 8 a year. And their salt-carrying capacity had been improved as well: whereas in the Tokugawa Period they might carry around 5,000 bales of salt, in the Meiji period this had increased to 6,000-7,000 bales, so there was an increase in scale as well. These improvements in the performance of cargo vessels in the early Meiji period were conducive to their continued existence until at least the mid-1900s. This reflected the fact that there were areas in which the economic rationality of these early-modern cargo vessels was still valid, and it was in these areas that the Japanese-style ships could still play an important role. In other areas, such as transoceanic voyages, the transport of travelers, regular services, and the trans-

${ }^{13}$ Kitamaebune were cargo vessels that sailed between Hokkaidō and the Töhoku district and Osaka via the Sea of Japan, to Shimonoseki, and then via the Inland Sea. They mainly carried salt and sake to the northern districts, and brought back from there kelp, herring, and fish fertilizer. 
port of large volumes of merchandise, it is not surprising to find steamships being introduced and used as quickly as possible, and in the early Meiji Period coexistence in separate spheres of activity in the maritime transport industry went on for some time. 